\title{
Incidence of oronasal haemorrhage in infancy presenting to general practice in the UK
}

\author{
Neil McIntosh and James Chalmers
}

\begin{abstract}
The frequency of oronasal haemorrhage in infancy was estimated from two national GP research databases (6\% UK population). When a case was identified, other presentations in the child over the first year were available from one dataset. In the first year haemoptysis is rare. In contrast, epistaxis (7-20 cases of per 10000 infants) was 10 times more common, and $14.3 \%$ of these infants had an injury at some other point in infancy, (four times greater than the general population). In general practice epistaxis may herald other trauma presentations, implying that such infants may be part of a high-risk group for injury.

Keywords

child abuse; child protection; epistaxis; haemoptysis; infant.
\end{abstract}

N McIntosh, DSc(Med), emeritus professor of child life and health, Department of Child Life and Health, Edinburgh, Scotland. J Chalmers, MSc, MRCGP, FFPH, consultant in public health medicine, Information Services Division, NHS National Services Scotland, Edinburgh, Scotland.

Address for correspondence

Neil McIntosh, Emeritus Professor of Child Life and Health, Department of Child Life and Health, 20 Sylvan Place,

Edinburgh EH9 1UW, Scotland.

E-mail: neil.mcintosh@ed.ac.uk

Submitted: 17 March 2008; Editor's response: 4 June 2008; final acceptance: 18 June 2008.

(-British Journal of General Practice.

This is the full-length article of an abridged version published in print. Cite this article as: $\mathrm{Br} J$ Gen Pract 2008; DOI: 10.3399/bjgp08X376122

\section{INTRODUCTION}

Blood issuing from the nose or mouth of an infant is rare in the first year or two of life and sometimes suggests significant underlying problems. ${ }^{1-4}$ This paper explores the epidemiology of oronasal haemorrhage in children attending general practices in the UK in the first 3 years of life.

\section{METHOD}

Details of the two datasets (QResearch, Nottingham, 5 years; and Information Services Division [ISD], Scotland, 8 years) and Read codes used are shown in Appendices 1 and 2, respectively. The numerators were any code indicating haemorrhage from the nose or mouth. The denominators were taken as the numbers of children registered in the database for each of the first years of life. In the ISD dataset it was possible to view all other reasons for attendance in the first year of life when an index haemorrhage was identified, and particular attention was paid to attendances for trauma or neglect.

\section{RESULTS}

The denominator was $6-7 \%$ of the population at this age. Table 1 shows the types of haemorrhage and age at which they occurred in the two datasets.

No episodes of trauma or neglect were seen in cases of haemoptysis, but seven (14.3\%; $95 \%$ confidence interval $[\mathrm{Cl}]=6.8$ to $27 \%$ ) of the 49 children with epistaxis had injuries recorded. Four children had head injuries at 25, 34, 40, and 44 weeks (all at different times from the recorded epistaxes); one had facial contusions at the time of the epistaxis (37 weeks); one had contusions and fractures of the rib and humerus, each at different ages from the epistaxis; and one had bruising, again recorded at an age different from the epistaxis. This figure of $14.3 \%$ contrasts with $3.3 \%(95 \% \mathrm{Cl}=2.9$ to $3.7 \%)$ of a nonoronasal haemorrhage infant group in the most recently available 3-year period (2003-2005).

\section{DISCUSSION}

Summary of main findings

Attendance for oronasal haemorrhage was 
uncommon. Epistaxis was uncommon in the first year and became increasingly common over the next 2 years. Haematemesis was half as common, and haemoptysis seven times less common and both became rare after the first year.

\section{Strengths and limitations of the study}

Blood issuing from the nose or mouth in an infant or young child is a disturbing sign for a parent to witness. Distinguishing haematemesis from haemoptysis or epistaxis in a young child can be difficult. This study therefore reviewed all the causes of oronasal haemorrhage in early childhood in two national general practice datasets.

The wide range of possible incidence for epistaxis in both datasets may reflect the inability within the datasets to distinguish the presenting complaint from a previous history.

\section{Comparison with existing literature}

No previous studies were found on the incidence of oronasal haemorrhage in general practice in young children, and there were few relating to hospital admissions or attendances.

A recent population study examining the epidemiology of oronasal haemorrhage presenting to hospital in the first 2 years of life showed, firstly, such haemorrhages are rare, with haemoptysis being rarer than epistaxis. ${ }^{2}$ Second, most cases of epistaxis are associated with trauma, and in a significant proportion child protection issues were raised. Third, it found that when there is no obvious trauma there are a number of serious underlying problems such as malignancy or thrombocytopenia. The hospital study left two open questions: firstly, would parents whose infant had a nose bleed or oronasal haemorrhage take them for a medical opinion? Alternatively, would attendance at the general practice make further hospital evaluation unnecessary? Whether parents take the problem seriously was addressed by a public survey organisation poll of 320 parents of children aged less than 5 years: $94 \%$ would seek immediate help either at their general practice or emergency department. ${ }^{5}$ Whether they would do this in real life is, of course, unknown.

\section{How this fits in}

Oronasal haemorrhage is rare in the first year of life. If there is no history of obvious accidental trauma, full investigation for serious problems such as a bleeding tendency or child abuse should be initiated.

Table 1. Type of haemorrhage and age group.

\begin{tabular}{lccc} 
& \multicolumn{3}{c}{$n$ (rate per 10 000/year) } \\
\cline { 2 - 4 } & Aged <1 years & Aged 1-2 years & Aged 2-3 years \\
\hline QResearch (5 years data) & 193591 & 224612 & 222974 \\
Denominator & $19(0.98)$ & $20(0.89)$ & $6(0.27)$ \\
Haemoptysis & $140(7.20)$ & $524(23.6)$ & $812(36.5)$ \\
Epistaxis & $3(0.15)$ & $23(1.02)$ & $30(1.36)$ \\
Bleeding gums & $67(3.46)$ & $45(2.00)$ & $29(1.30)$ \\
Haematemesis & $11(0.57)$ & $2(0.08)$ & $1(0.04)$ \\
Pulmonary haemorrhage & & & \\
ISD (8 years data) & 25282 & - & - \\
Denominator & $4(1.58)$ & - & - \\
Haemoptysis & $49(19.7)$ & - & - \\
Epistaxis &
\end{tabular}

QResearch = predominantly England and Wales database; ISD = Information Services Division of the Scottish Health Service database.

The emergency department and hospital data suggested that the incidence of epistaxis in the first year of life that presents to hospital is about 1 case per 10000 - all children arriving at the emergency department being admitted. This study of general practice attendance for oronasal haemorrhage demonstrates an incidence of between 7 and 20 cases per 10000 infants per year, some 10 times more common than the numbers attending a children's hospital.

The Scottish ISD dataset also indicates that cases of epistaxis in infancy are four times more likely to have some other significant injury at some stage in the first year of life than those infants who do not have an epistaxis. In the hospital study, ${ }^{2}$ the high incidence of injuries was concurrent with the epistaxis and, in retrospect, there were child protection concerns in approximately half of these 'accidental' injuries associated with the epistaxis. It is therefore of concern that other injuries occurred in seven out of the 49 infants presenting at the general practice with epistaxis, but, in contrast, on different occasions to the epistaxis. There was no information available in the GP dataset on whether concerns about abuse were raised at the time of either the epistaxis or the traumatic injuries.

\section{Implications for clinical practice}

Oronasal haemorrhage in infancy should be taken seriously if it arises spontaneously, and may flag up potential child protection concerns if associated with trauma.

\section{Ethical approval}

Sanction of a research ethics committee was not required for this project as only anonymised data were used. However, the first author (Neil Mclntosh) had to submit the protocol for peer review and consideration by the QResearch management group and the privacy advisory 
committee of the ISD before receiving data

\section{Competing interests}

The authors have stated that there are none

\section{Acknowledgements}

Access to the QResearch database was by application to Professor Julia Hippisley-Cox, who also provided valuable assistance. Ahmed Mahmoud and Dr Annemarie Van Heelsum provided the data from the general practice database of the ISD.

\section{Discuss this article}

Contribute and read comments about this article on the Discussion Forum: http://www.rcgp.org.uk/bjgp-discuss

\section{REFERENCES}

1. Pallin DJ, Chng YM, McKay MP, et al. Epidemiology of epistaxis in US emergency departments, 1992 to 2001. Ann Emerg Med 2005; 46(1): 77-81.

2. McIntosh N, Mok JY, Margerison A. Epidemiology of oronasal hemorrhage in the first 2 years of life: implications for child protection. Pediatrics 2007; 120(5): 1074-1078.

3. Okada T, Sasaki F, Itoh T, et al. Bleeding disorder as the first symptom of biliary atresia. Eur J Pediatr Surg 2005; 15(4): 295-299.

4. Sandoval C, Dong S, Visintainer P, et al. Clinical and laboratory features of 178 children with recurrent epistaxis. J Pediatr Hematol Oncol 2002; 24(1): 47-49.

5. McIntosh N, Haines L, Baumer JH. Parents reactions to nose bleed and salt ingestion in infancy. Arch Dis Child 2008; 93(5): 449. 


\section{Appendix 1. Details of the data sets.}

\section{Datasets}

Two general practice datasets were available to determine the incidence of oronasal haemorrhage in children less than 3 years of age and additional conditions that might occur at the same time as their presentation with such haemorrhages.

- The QResearch database held by the Department of General Practice at the University of Nottingham. Five years of data were evaluated (2002-2006) for all GP consultations for oronasal haemorrhage occurring in the first 3 years of life.

- The Practice Team Information database of the Information Services Division (ISD) of the Scottish Health Service. Eight years of data were assessed for epistaxis and haemoptysis in the first year of life, together with the reasons for all other attendances to either a GP or attached nursing staff in these infants when one of these problems was positive.

Both data sources aim to collect data from a general spectrum of the population. They collect data in slightly different ways and this allows certain questions to be answered more clearly from one dataset compared with the other. Both datasets are reliant on the quality of GP record keeping.

In the QResearch dataset, the date of birth of all patients is converted (for anonymity) to the first of January that year, and the year of age is related to that date. The date of each event is, however, kept accurately. This can lead to some episodes of data in the first year of a patient's life being classified in the second year, and certain episodes in the second year of life being classified in the third year. Thus, although a comparison of incidences for the first 3 years of life is possible, an accurate estimate of incidence is not possible for each year. There was no way of knowing in the QResearch dataset whether the problem was active or in the history.

In the ISD database, all attendances at the general practices are logged with their attendant diagnosis and postnatal age. It was therefore possible to identify whether the haemorrhage was an active problem and also what other problems had led to general practice attendance in the first year for all children who presented with an oronasal haemorrhage.

\section{Codes}

The group of Read codes used to identify oronasal haemorrhage is shown in Appendix Table 2.

If any of these codes were positive in the ISD dataset, all other presentations to the general practice (nurse, health visitor, or doctor) were reviewed, with particular attention to problems of trauma or neglect.

\begin{tabular}{|c|c|c|}
\hline Read code & Read definition & Category \\
\hline $14 \mathrm{C} 8$ & $\mathrm{H} / \mathrm{O}$ : haematemesis & Haematemesis \\
\hline 172 & Blood in sputum - haemoptysis & Haemoptysis \\
\hline $172-1$ & Blood in sputum - symptom & Haemoptysis \\
\hline $172-2$ & Haemoptysis - symptom & Haemoptysis \\
\hline 1928 & Bleeding gums & Bleeding gums \\
\hline $1 \mathrm{C6}$ & Nose bleed symptom & Epistaxis \\
\hline $1 \mathrm{C6}-1$ & Epistaxis symptom & Epistaxis \\
\hline $1 \mathrm{C} 62$ & Has nose bleeds - epistaxis & Epistaxis \\
\hline $1 \mathrm{C} 6 \mathrm{Z}$ & Nose bleed symptom NOS & Epistaxis \\
\hline 2556 & $\mathrm{O} / \mathrm{E}-$ bleeding gums & Bleeding gums \\
\hline $2 \mathrm{D} 25$ & O/E - epistaxis & Epistaxis \\
\hline J680 & Haematemesis & Haematemesis \\
\hline J680-1 & Vomiting of blood & Haematemesis \\
\hline R047 & [D]Epistaxis & Epistaxis \\
\hline R063 & [D]Haemoptysis & Haemoptysis \\
\hline R0630 & [D]Cough with haemorrhage & Haemoptysis \\
\hline R0631 & [D]Pulmonary haemorrhage NOS & Pulmonary haemorrhage \\
\hline $\mathrm{R} 063 z$ & [D]Haemoptysis NOS & Haemoptysis \\
\hline
\end{tabular}

